\title{
BASES PARA UNA DECONSTRUCCIÓN DEL CONCEPTO DE RESCISIÓN POR LESIÓN
}

\author{
BASES FOR DECONSTRUCTING THE CONCEPT OF LAESIO ENORMIS
}

\author{
Nathalie Walker SiLVA*
}

\begin{abstract}
RESUMEN: El objetivo de este trabajo es reestructurar el concepto de rescisión, articulándolo sobre las bases que cimentan su origen, a fin de reformular la manera en que se relaciona con otros conceptos, como el de autonomía de la voluntad o el de fuerza obligatoria del contrato, con los cuales presenta una aparente colisión. En el afán de deconstruir el concepto de rescisión también subyace la intención de reposicionar a esta forma de ineficacia y reflexionar en torno a las funciones que le competen.

Una conclusión general que se extrae de la investigación realizada es que la verdadera utilidad y fortaleza de la rescisión por lesión es el constituir una manifestación concreta de un afán de justicia conmutativa que persigue resguardar la buena fe en la contratación y corregir desigualdades odiosas que, de no existir este remedio, estarían destinadas a perpetuarse.
\end{abstract}

Palabras clave: Rescisión, lesión contractual, autonomía de la voluntad, libertad contractual, justicia contractual.

ABSTRACT: The objective of this paper is to restructure the concept of rescission, articulating it on the bases that support its origin, to reformulate the way it relates to other concepts such as the will theories or the binding force of contracts, with wich it presents an apparent collision. In the effort to deconstruct the concept of rescission also underlies the intention of setting properly this inefficacy type and reflect about the functions that are their responsibility.

A general conclusion drawn from the research is that the real usefulness and strength of laesio enormis is that it constitutes a concrete manifestation of a desire for commutative justice which seeks to safeguard good faith in hiring and to correct odious inequalities that would be destined to perpetuate themselves in the absence of this remedy.

Key words: Rescission, laesio enormis, autonomy of the will, contractual freedom, contractual justice.

\section{PREMISAS PARA UN EJERCICIO DE DECONSTRUCCIÓN}

De acuerdo a la definición dada por el diccionario de la Real Academia Española de la Lengua, una deconstrucción es "un desmontaje de un concepto o de una construcción intelectual por medio de su análisis, mostrando así contradicciones y ambigüedades”. Esta idea es plenamente concordante con la naturaleza de las materias que abordaremos en este

\footnotetext{
* Licenciada en Derecho, Pontificia Universidad Católica de Chile. Magíster en Ciencia Jurídica y Candidata a Doctora en Derecho por la Pontificia Universidad Católica de Chile. Profesora de Derecho Procesal en la Universidad Adolfo Ibáñez y en la Universidad Bernardo OHiggins. Dirección postal: Diagonal las Torres 2640, Peñalolén, Santiago de Chile. Dirección electrónica: nathalie.walker@uai.cl
} 
trabajo, cuyo objetivo consiste en reestructurar el concepto de rescisión, articulándolo sobre las bases que cimientan su origen.

Estudiar la rescisión por lesión implica, en gran medida, determinar el ámbito que los ordenamientos han reservado -en las distintas épocas y lugares- a la autonomía privada en materia de contratación.

Si examinamos las distintas actitudes que las sociedades han adoptado ante la rescisión, veremos que están necesariamente condicionadas por la tensión entre el respeto a la autonomía privada y el principio de justicia contractual. De tal manera que, si la obediencia al primero de estos principios es irrestricta, la rescisión no tendrá cabida alguna. A la inversa, a medida que se concede una mayor importancia a los mandatos de la justicia contractual, será frecuente que el remedio de la rescisión esté presente para proteger al contratante lesionado por las estipulaciones de un contrato que -aunque con un contenido aparentemente acorde a la ley- le resulta manifiestamente injusto.

Es a la segunda alternativa a la cual se inclinan todos aquellos ordenamientos que dan cabida a la rescisión por lesión ${ }^{1}$, los que, a su vez, se basan en la concepción tradicional de justicia. Esta noción concibe a la justicia como propiedad de una relación entre personas cuya esencia es la idea de igualdad y que se funda en el reconocimiento de la dignidad de todo individuo de la especie humana².

Para efectuar la labor de deconstrucción del concepto de rescisión, es imprescindible efectuar un examen previo del principio de autonomía de la voluntad y del aparente antagonismo entre libertad y justicia contractual. Este punto de partida hará posible la posterior revaloración de la rescisión por lesión, que permita superar aparentes contradicciones internas, reinterpretando su utilidad y sus efectos en base a su finalidad, que es, en definitiva, la que ha permitido que esta institución perdure en el tiempo, más allá de las particularidades de cada caso.

\section{AUGE Y CAÍDA DE LA CONCEPCIÓN CLÁSICA DEL CONTRATO}

La concepción clásica del contrato es una teoría que tiene como postulado central la afirmación de que la autonomía de la voluntad ${ }^{3}$ es el fundamento de la fuerza obligatoria

\footnotetext{
1 De ello dan cuenta: el Código francés de 1804, el Código Civil austríaco (1811), el Código Civil boliviano antiguo (1831), el Código italiano de 1865, el Código Civil peruano antiguo (1936), el Código Civil chileno (1855), el Código Civil alemán (BGB, 1900), el Código suizo (en revisión del 30 de marzo de 1911), el Código Civil italiano de 1942, el Código austríaco (1911), el Código mexicano (1928), el Código griego (1946), el Código húngaro (1960), el Código etíope (1960), el Código Civil polaco (1965); el Código guatemalteco (1963); el Código portugués (1967), el Código Civil argentino (el original de Vélez SARsfield no sancionaba la lesión, pero la ley que lo reformó en 1968 -LeY 17.711-, la introdujo en el art. 954. Actualmente, el Código Civil y Comercial de la Nación, de 2014, regula la lesión dentro de los vicios de los actos jurídicos, en el art. 332), el Código boliviano (1977); el nuevo Código Civil peruano (1984); el nuevo Código Civil paraguayo (1986), etc.

2 Confrontar con Pedrals (2014) p. 412. Producto de esta doctrina, recogida en nuestro ordenamiento, es que para nosotros adquieren importancia los conceptos de "precio justo" y de "prestaciones equivalentes", conceptos ambos que constituyen el núcleo de la laesio ultra dimidium o laesio enormis.

3 Emplearemos aquí, la mayor parte de las veces, la denominación "autonomía de la voluntad” por tratarse de la nomenclatura más difundida en la doctrina nacional. Véase, por todos: López (2010) p. 3; AcCATiNo (2015)
} 
del contrato y es el principio básico que sustenta la regulación del contrato por el Derechó ${ }^{4}$.

La autonomía de la voluntad es, a su vez, una doctrina de filosofía jurídica que postula que las obligaciones contractuales descansan en la soberanía de la voluntad de las personas 5 . De este modo, la concepción clásica del contrato "sustenta la teoría general del contrato en el principio de la autonomía de la voluntad, el cual descansa en la siguiente idea matriz: la voluntad, que se basta a sí misma y que no es contraria al ordenamiento jurídico, da lugar a la autonomía de la voluntad como fuente de los derechos personales que emanan de los contratos" ${ }^{6}$. En este modelo de pensamiento, el dogma bizantino y oriental de la voluntas -poderosamente favorecido por el individualismo de los siglos intermedios-, pasó a convertirse, gracias al influjo del Code Napoléon, en el centro del Derecho moderno

La autonomía de la voluntad se materializa con alcances diversos en los ordenamientos jurídicos, dependiendo del rango de acción que se reconozca a las relaciones jurídicas privadas, pero, si algo puede concluirse al respecto, es que no existe ningún ordenamiento que no la reconozca ${ }^{8}$.

Desde la perspectiva voluntarista, la época de formación del contrato aparece dominada por dos ideas matrices que son, a la vez, subprincipios de la autonomía de la voluntad: el consensualismo y la libertad contractual; mientras que, si se mira al contrato como una relación jurídica ya creada y en funcionamiento, las ideas fundamentales de la fuerza obligatoria y del efecto relativo de los contratos también se hallan impregnadas del principio de la autonomía de la voluntad ${ }^{9}$.

Se produce aquí un fenómeno muy particular, consistente en la consideración de la autonomía privada como algo preexistente a la valoración del ordenamiento jurídico, el que solo se limitaría a reconocerla y a proteger los actos emanados de aquella ${ }^{10}$.

\section{La liberTad CONTRACTUAL Y LA AUTONOMÍA DE LA VOLUNTAD CONCEBIDAS COMO DOGMAS}

En la época en que inserta el fenómeno de la codificación, comienza a concebirse la voluntad como un sinónimo de libertad, que muta hasta convertirse en el denominado "dogma de la autonomía de la voluntad"11.

p. 40; Troncoso y Álvarez (2014) p. 10]. Aunque reconocemos que en Derecho comparado suele ser más común la utilización del concepto de "autonomía privada".

4 Confrontar Accatino (2015) p. 39.

5 Confrontar López (2003) p. 107. En un sentido similar, Díez-PiCAZo y Gullón (1995) vol. I, p. 480.

6 Barcia (2006) p. 164.

Confrontar De Martino (2005) p. 19.

8 Confrontar Flume (1998) p. 23.

9 Confrontar López (2010) p. 4.

10 Para GuZmán BRITo, esta concepción subjetivista y voluntarista de los fenómenos jurídicos resulta inadmisible [GuZMán (2005) p. 205].

11 Respecto de la teoría voluntarista -o del dogma de la voluntad-como base del Derecho de contratos en los Códigos, conviene revisar un reciente trabajo de Daniela AcCATino. En él, la autora explica que hay diversos trabajos historiográficos recientes que demuestran que el dogma de la voluntad constituye más bien un mito jurídico, debido a que ni en los Códigos decimonónicos, ni en las fuentes que los inspiraron, ni en los trabajos 
Debido a la influencia del liberalismo, la libertad contractual -entendida, en esencia, como la facultad de contraer obligaciones y de determinar el contenido del contrato- ${ }^{12}$ deviene en un bien jurídico que merece la máxima protección ${ }^{13}$. Manifestación concreta de esto es que los Códigos civiles abandonan los formalismos y formulismos que antes constituían una parte fundamental del acuerdo de voluntades, para dar paso al principio espiritualista en la celebración del contrato: lo que realmente importa es que dos o más personas acuerden la realización de un negocio y no la forma en que dicho acuerdo se plasme ${ }^{14}$.

Bajo el imperio de ese dogma, son las partes quienes mejor pueden velar por sus intereses, pudiendo -en teoría- crear un perfecto equilibro entre lo que desean obtener y lo que darán a cambio. Mediante una especie de mantra repetido con esmero, los postulados iusracionalistas logran convencer a todos que el contrato, en cuanto es voluntario, es necesariamente justo. La única preocupación existente, en este orden de cosas, es eliminar toda traba a la libertad contractual, para que esta traiga consigo el bienestar general de la sociedad, en una ecuación que siempre contempla la variable justicia, no porque se la considere especialmente digna de tutela, sino porque es un producto inherente a la voluntad libremente expresada.

Tal exaltación de la autonomía de la voluntad tiene lugar en una época que se caracteriza por el desenvolvimiento del comercio y de la industria, y en la que florece la economía liberal bajo el principio del laissez faire, laissez passer; el que, a su vez, repelía las intervenciones estatales y las trabas a la libertad contractual, bajo la premisa de que el libre juego de la oferta y la demanda y el egoísmo individual son la causa de la felicidad y la prosperidad de las naciones ${ }^{15}$. Se produce, en consecuencia, el fenómeno de la "mercantilización del Derecho", que postula la necesidad de priorizar la seguridad del tráfico jurídico. Así, la autonomía de la voluntad pasa de ser una expresión de respeto a la libertad individual, a ser, más bien, una eficaz herramienta para el desarrollo del comercio, que presta más atención a lo declarado que a lo efectivamente querido por las partes ${ }^{16}$.

preparatorios elaborados por sus redactores existen indicios de una concepción voluntarista. Según la autora, lo que sí existiría es "una clara continuidad con una teoría del contrato que hunde sus raíces en la escolástica tardía y en la que las nociones de virtud y justicia conmutativa tienen todavía una presencia significativa” ACCATiNO (2015) p. 42. En sentido similar, PizArro (2004) pp. 228 y 229. Así, la autonomía de la voluntad no sería un concepto introducido por los autores "clásicos", sino que, paradójicamente, habría sido introducido por los autores que efectuaron los primeros análisis críticos de esos planteamientos, a fines del siglo XIX y comienzos del siglo XX Cfr. Accatino (2015) pp. 39-42. En sentido similar, Pizarro (2004) pp. 225-237. Con todo, y pese al descubrimiento reciente de este "mito", la autora citada reconoce que esto no basta para desechar sin más a la teoría clásica, puesto que esta "podría ofrecer una reconstrucción sistemática coherente y completa del Derecho de contratos, a pesar de elaborada con posterioridad a su dictación. Aunque se trate de una teoría desarrollada después de los Códigos, la teoría voluntarista podría ser una herramienta útil para comprender y sistematizar el Derecho de contratos y para justificar soluciones a los problemas interpretativos que presente" [ACCATINo (2015) p. 44].

12 Confrontar López (2010) p. 109 y 213.

13 Confrontar Martín (1995) p. 25.

14 Confrontar Lasarte (1991) pp. 269 y 270.

15 Confrontar Díez-Picazo y Gullón (2012) vol. II, Tomo I, p. 21.

16 Confrontar De Castro (2008) vol. III, p. 15. 
En concordancia con esa concepción, los Códigos contemplan normas que tienden a ampliar lo máximo posible el campo de la eficacia jurídica de los contratos ${ }^{17}{ }^{18}$. Si el contrato es por esencia justo, ya que proviene de un acuerdo libremente consentido, toda intervención que modifique la voluntad expresada por las partes será vista como algo negativo o, más aún, como algo innecesario en un sistema cercano a la perfección, que calibra con precisión el funcionamiento de cada una de sus piezas. En este pequeño cosmos del contrato, carece de sentido el dar cabida a un control de la usura o la lesión ${ }^{19}$, en el entendido de que si los contratantes han pactado condiciones del contrato que resultan ser perjudiciales para ellos, es porque así lo han querido.

De esta forma, el principio de la fuerza obligatoria del contrato o pacta sunt servanda es un corolario lógico del dogma de la autonomía de la voluntad y es, a su vez, uno de los pilares básicos del derecho de contratos, siendo reconocido por gran parte de los ordenamientos y consagrado tanto en los Códigos decimonónicos como en los contemporáneos ${ }^{20}$.

En términos generales, la fuerza obligatoria del contrato $^{21}$ implica que las partes deben respetar las obligaciones válidamente contraídas, teniendo estas últimas una fuerza vinculante para aquellas y, por tanto, exigibilidad para su cumplimiento ${ }^{22}$. Se otorga, en suma, plena eficacia obligatoria al contrato, el que obliga -y en sus propios términos-, si ha sido libremente consentido ${ }^{23}$. En su concepción tradicional, además, lleva incorporada la intangibilidad del contrato, de modo que ni las partes (salvo por mutuo acuerdo) ni el juez podrían cambiar los términos de un contrato válidamente celebrado, con independencia de cuánto hayan cambiado las condiciones existentes a su época de celebración ${ }^{24}$.

17 El Código Civil francés es un digno exponente de la concepción liberal de la organización social y económica: en su articulado subyace la idea de que el desenvolvimiento de la voluntad, en sus múltiples manifestaciones, conducirá a un equilibrio social satisfactorio debido la necesidad de la voluntad concurrente de todos los sujetos participantes del mercado Cfr. Díez-Picazo y Gullón (2012) vol. II, Tomo I, p. 21.

18 Una concreción de esto es el hecho de que la autonomía de la voluntad se encuentra presente no solo en la formación del contrato, sino en todo su proceso de desarrollo. Incluso tiene cabida en las eventuales ineficacias que pudieran afectarlo, como ocurre con la posibilidad de saneamiento de la nulidad relativa por voluntad de las partes, cuestión que el Código Civil chileno trata entre los artículos 1693 a 1697 Cfr. BARCIA (2009) Tomo II, p. 37.

19 En este sistema de economía liberal, se postula que no existe un precio que pueda ser objetivamente justo, porque quien los determina es la dinámica del mercado. Por esta razón, el Código Civil español, digno exponente de su época, constituye un claro ejemplo de normativa que no contempla a la rescisión como un remedio al desequilibrio en las prestaciones de un contrato. En otras palabras, no habrá abusividad de los precios en un mercado libre Cfr. Díez-Picazo (2007) Vol. I, p. 58.

20 Confrontar Momberg (2013) p. 10.

21 Una síntesis de las distintas teorías que explican la obligatoriedad del acuerdo contractual, puede encontrarse en Soto (2008) pp. 109 y 110.

22 Confrontar Momberg (2013) p. 10.

23 En cuanto a la obligatoriedad del contrato, BETTı añade que el contrato es protegido por el Derecho no en cuanto sea un mero arbitrio de los particulares, sino en cuanto ese intento práctico de las partes se encuadre y se tipifique -según la exigencia del tratamiento normativo- en funciones económico-sociales que sean dignas de tutela jurídica. Confrontar. BetTi (1975) p. 346. En igual sentido se pronuncia DíEz-PicAzo, al señalar que el contrato no obliga solamente por respeto a la palabra empeñada, sino también porque es un cauce institucional de realización de fines e intereses. Confrontar. Díez-Picazo (2007) p. 141.

24 Confrontar Momberg (2013) p. 10. 
En este Derecho de contratos, las valoraciones de justicia o injusticia de los resultados contractuales quedan subordinadas al postulado de justicia de que el precepto al que las partes se someten sea obra de su iniciativa y autonomía. Lo justo, lo exigido por la dignidad de las personas, es un mundo de contratos libres ${ }^{25}$. Por consiguiente, en este orden de cosas, "los enriquecimientos conseguidos a través de contratos libres no son nunca injustos. Corrobora esta idea el hecho de que, por lo menos a partir de la entrada en vigor de las codificaciones del siglo XIX, el Derecho civil abandonara la vieja idea escolástica de los precios justos, si prescindimos de algunos residuos como la rescisión por lesión ultradimidium en los ordenamientos que la acogen" ${ }^{26}$.

Producto de esos dogmas, en los Códigos que incorporan la lesión como una causal de rescisión, en general, aquella solo cumplirá tal función en el evento en que haya existido un vicio que atente contra la libertad contractual ${ }^{27}$. Es decir, en cuanto exista una limitación "clásica" a la autonomía privada, manifestada en la forma de vicios de la voluntad: error, fuerza o dolo. La injusticia puede estar, entonces, en la forma de producirse la vinculación contractual: por ejemplo, porque no ha sido libre; pero si la parte de un contrato injustamente celebrado se enriquece, ello no pasará de ser una forma de valorar socialmente su comportamiento. Desde el punto de vista jurídico no habrá más alternativa que recurrir a la ineficacia del contrato ${ }^{28}$. En los demás casos, la regla será que los contratantes deberán cumplir las obligaciones que engendra el contrato porque las han pactado y no por las ventajas o desventajas que les reporten.

\section{El QUIEBRE DEL PARADIGMA DE LA IGUALDAD EN LA CONTRATACIÓN}

El otro presupuesto ideológico liberal es el de la existencia de igualdad en la contratación, postulado que se encuentra en la base de la regulación del contrato y dispone que las partes se encuentran en un plano de igualdad y tienen la misma capacidad económica para llevar a cabo las negociaciones inherentes a la formación del contrato.

En consecuencia, la igualdad -bandera de lucha de la revolución francesa- también alcanzó el ámbito jurídico. Al abolirse los privilegios, este gran triunfo de la burguesía permitiría que todos los ciudadanos fuesen considerados iguales ante la ley, asumiendo que la igualdad jurídica presuponía, asimismo, una igualdad de carácter económico.

Pero pronto la doctrina vio su desengaño, al advertir que esa presunción de igualdad y de plena libertad de decisión no pasaba de ser un sarcasmo; la realidad demostró con pruebas contundentes que si existe una inmensa masa de personas que poco o nada tienen,

\footnotetext{
25 Cfr. De la Cámara y Díez-Picazo (1988) p. 52. Al respecto, Amparo Montaña nos señala que: "esta nueva visión considerará que el único precio justo es el que las partes hayan pactado libremente. Ya no será necesario que cada contratante reciba tanto valor objetivo como el que da, será suficiente, en los contratos onerosos, la existencia de recíprocas prestaciones. Así, la única justificación de la supervivencia de la laesio ultra dimidium se encontrará en reconducir sus presupuestos objetivos -equivalencia económica- a presupuestos subjetivos -libre consentimiento-" Montaña (1999) p. 81.

26 De la Cámara y Díez-Picazo (1988) p. 52.

27 Véanse, por todos, el Código Civil francés de 1804 y el Código Civil chileno.

28 Confrontar De la Cámara y Díez-Picazo (1988) p. 52.
} 
frente a una clase social que detenta la mayor parte de la riqueza, es imposible hablar de igualdad ${ }^{29}$.

También resultó ser inexacto que la libertad contractual produzca siempre unos resultados económicos socialmente útiles, ya que los hombres -en uso de una autonomía considerada como soberana- no se orientan de ordinario a las actividades más convenientes para lograr el interés general, sino a las ocupaciones que les sean más rentables, en búsqueda de un máximo lucro individual con el menor sacrificio posible ${ }^{30}$.

$\mathrm{Al}$ caer el postulado de la igualdad formal ${ }^{31}$, arrastra consigo también a la libertad contractual -porque la primera sustenta y da sentido a la segunda-. Así, si los débiles son explotados por los poderosos es inviable seguir sosteniendo que los sujetos son absolutamente libres, pues esa abstracta libertad individual no siempre arrojará un resultado digno de tutela y, por tanto, no puede ser un principio absoluto del orden jurídico-económico, pues solamente tiene un significado concreto para quienes cuentan - en un principio- con un cierto número de oportunidades de actuar, mientras que implica una ausencia de libertad para esa mayoría que parte con muy pocas o nulas oportunidades ${ }^{32}$.

El dogma de la autonomía voluntad desaparece, entonces, cuando se advierte que tras él se encontraban los intereses de quienes saben que son poseedores de una voluntad más fuerte; y cuando se torna evidente que tanto los límites tradicionales de la autonomía como la teoría de los vicios de la voluntad no son suficientes para la corregir los abusos más patentes ${ }^{33}$.

La consecuencia que fluye de todo lo anterior es que, si han fallado los postulados, será necesario revisar también el resultado. De tal modo, si estamos en condiciones de apreciar que del contrato no siempre surge una equitativa regulación de intereses, si la justicia no es una consecuencia automática del contrato, esa justicia deberá, entonces, ser garantizada por la ley y por el juez ${ }^{34}$.

De esta forma, los postulados liberales han sido sustituidos o complementados por otros que reflejan las inquietudes en torno a la necesidad de justicia en la contratación. La intervención del Estado en la vida económica se reclama cada vez con más intensidad ${ }^{35}$,

29 Confrontar Díez-Picazo y Gullón (2012) vol. II, Tomo I, p. 21. En este punto, Pasquau matiza la explicación tradicional dada a este fenómeno. Para este autor "la igualdad entre las partes contratantes no era un presupuesto de carácter fáctico (convicción sobre cómo es la realidad), sino más bien un presupuesto lógico del que quiso políticamente partirse en la codificación” PASQUAU (2011) p. 490. De modo que la explicación no provendría de una equivocada e ingenua percepción de la realidad, sino que de una opción de política legislativa, producto de la cual los Códigos se limitaron a regular los casos más extremos de falta de idoneidad del consentimiento contractual: por un lado, los supuestos de error, fuerza y dolo, y por otro, la falta de capacidad de obrar. Fuera de esos casos, las diferencias entre las partes son un asunto que atañe al cuidado de sus propios intereses" PASQUAU (2011) pp. 490 y 491.

30 LÓPez (2003) p. 197.

31 Se habla de igualdad formal, en contraposición a una igualdad real, o de contenido concreto.

32 Confrontar MarTín (1995) p. 30.

33 Confrontar Martín (1995) p. 30; Ordoqui (2011) p. 66.

34 Confrontar MarTín (1995) pp. 30 y 31.

35 Esto ha provocado lo que De CASTRO denomina la "aporía de la autonomía privada". Esta consiste en que el Estado, en su afán de tutelar la autonomía de la voluntad, debe calificarla, definirla y limitarla. Dicha actuación armonizadora de las libertades individuales, emprendida por la fuerza expansiva de la Administración, la 
ya sea para que evite los obstáculos que impidan el correcto funcionamiento de las fuerzas naturales del mercado, o para que imponga un cierto orden dentro del cual deban actuar los sujetos; o, incluso, para que sustituya a los operadores económicos existentes, en ciertos $\operatorname{casos}^{36}$. En cualquier caso, la intervención del Estado en la órbita de la autonomía de la voluntad también habrá de estar limitada, para impedir que la ahogue o suprima, en el entendido que se quiera continuar con un sistema social de libertades ${ }^{37}$.

\section{LA NECESIDAD DE RESGUARDAR LA EQUIDAD EN EL CONTRATO}

En la práctica, pueden presentarse casos en que es oportuno atenuar el rigor de las normas abstractas, para evitar que el summum ius se convierta en summa iniuria. En esos casos es preciso recurrir a la equidad, "mediante la cual el Derecho adquiere elasticidad mayor y una mayor idoneidad para adaptarse al caso particular ${ }^{38}$. La equidad es, por lo tanto, un precioso instrumento jurídico moderador de la rigidez, algunas veces excesiva, de la norma jurídica" ${ }^{39}$.

En virtud de su carácter contingente, la equidad está íntimamente relacionada con la oportunidad, constituyendo un instrumento muy eficaz de progreso, a diferencia de lo que acontece con la justicia, que es inmóvil e inmutable por naturaleza. En efecto, la idea de justicia es inmutable y siempre igual a sí misma, mientras que la equidad recibe la influencia del medio en que se desenvuelve, pudiendo acomodarse a las condiciones de tiempo, lugar, edad, sentimientos, intereses y tradiciones que la circundan; constituyendo todas estas, cosas que necesitan ser ponderadas mediante una labor continuamente nueva ${ }^{40}$. En cualquier caso, y pese a que desde el punto de vista positivo la equidad no debe identificarse con la justicia, no se puede negar que la adopción y la introducción de la equidad en el sistema responde a un verdadero principio de justicia ${ }^{41}{ }^{42}$.

Cuando el ideal supremo de la igualdad, perseguido por políticos y pensadores, se consideraba inalcanzable, la práctica enseñó a atemperar los vicios que se oponían a dicha igualdad, con la libertad y con la evolución sucesiva -y relativamente rápida- de la equidad

impulsará, precisamente, a actuar a costa de la misma autonomía que pretende proteger Confrontar DE CASTRO (2008) vol. III, p. 17.

36 Confrontar Díez-Picazo y Gullón (2012) Vol. II, Tomo I, p. 21.

37 Confrontar Díez-Picazo y Gullón (2012) Vol. II, Tomo I, p. 22.

38 Esta idea proviene de la antigua aequitas romana, ideal de justicia y aspiración de toda norma jurídica. En la Roma antigua se invocaba con frecuencia la equidad cuando el pretor introducía una interpretación ajustada a nuevas realidades, a la conciencia social, a las circunstancias de un caso particular o a la ausencia de regulación, suponiendo todo ello una innovación con arreglo al ius civile que se efectuaba atendiendo a las exigencias de justicia en el caso concreto. Confrontar. Fernández (2011) p. 29.

39 Pugliatti (1943) p. 38.

40 Confrontar CazZAniga [apud CASTejón (1911) pp. 158 y 159].

41 Confrontar Pugliatti (1943) pp. 38 y 39.

42 En tal sentido, "la idea de que la equidad está esencialmente vinculada a la justicia, atraviesa la historia cultural del Occidente, incluyendo doctrinas jusnaturalistas, Derecho romano y planteamientos doctrinarios sociales actuales" Pedrals (2011) p. 86. 
hacia mejores condiciones ${ }^{43}$. De esta forma, esta exigencia de justicia aplicada al contrato abarca, además de la justicia conmutativa, a un conjunto de reglas como la utilidad social, la lealtad, la solidaridad, la buena fe, la proporcionalidad, etc., que son partes de un mismo todo.

Una vez que la doctrina se percata de que los postulados iusracionalistas son absolutamente insuficientes para resguardar la justicia en el contrato ${ }^{44}$, se verifican cambios importantes que, progresivamente, permiten situar a la justicia por sobre la libertad contractual.

Una consecuencia vital de lo anterior es que el contrato será protegido por el Derecho no solo por tratarse de un acuerdo de voluntades, sino además -y principalmente- en cuanto contenga una regulación de intereses que sea equitativa para ambas partes. Tal como reconocía SALEILLES, hoy en día es la voluntad la que está al servicio del Derecho y no al revés; y, por lo mismo, no es posible decir: "esto es justo porque es querido", sino: "esto debe ser querido porque es justo" 45 .

Este nuevo esquema de pensamiento también permite revalorar la utilidad del principio de la equivalencia entre las prestaciones, el que comienza a considerarse legítimo, siendo el resultado de la lógica inherente a la justicia contractual ${ }^{46}$. Dicho principio ha de inspirar a todo el Derecho contractual y dar un nuevo contenido al concepto de onerosidad, debiendo ser concebida como "un control sobre la proporción de las concretas prestaciones en los intercambios onerosos que conduzca a negar tutela jurídica a todos aquellos

43 Confrontar. Cazzaniga [apud Castejón (1911) p. 156].

44 Un buen ejemplo de este cambio de mentalidad puede apreciarse en Duguit, quien afirma, en cuanto al dogma de la autonomía de la voluntad: "Como construcción lógica, es perfecta (...). Pero desgraciadamente, esta construcción no concuerda con los hechos. En un momento dado, ese sistema ha podido tener razón de ser. Podía adaptarse a una sociedad esencialmente individualista, como la sociedad romana y hasta como las sociedades europeas y americanas de comienzos del siglo XIX. Pero está en oposición absoluta con las tendencias socialistas y asociacionistas de nuestra época. Los jurisconsultos, todavía numerosos, que han permanecido fieles a la concepción individualista y metafísica, en la que ven un dogma intangible, realizan esfuerzos desesperados, prodigios de sutileza para comprender, cueste lo que cueste, en esos viejos cuadros demasiado estrechos, todos los hechos tan complejos del mundo moderno" Duguit (1912) p. 58.

45 Saleilles (1901) p. 351.

46 Aunque esta no es una idea novedosa, sino más bien una revaloración de una idea antigua: precisamente, la necesidad de que los bienes que se intercambian en una compraventa sean equivalentes, es un postulado que ya está presente en el pensamiento de Luis de Molina. Para este autor, como para los demás escolásticos, el criterio diferenciador de los precios en justos e injustos no es otro que la equivalencia. Así, será justa la compraventa en la que el precio pactado respete la equivalencia entre los bienes intercambiados y será injusta en la que no se respete. De igual modo, será justo el precio que establezca la equivalencia y será injusto el que no la establezca [Confrontar. Molina (1981) p. 43. Una idea similar encontramos también -más atrás en el tiempo- en Santo Tomás de Aquino. En su Tratado de la Justicia, considera como un acto contrario a la justicia conmutativa el vender a un precio mayor del que se estime por justo. Así, señala que: "la compraventa se utiliza para común utilidad de ambas partes; y es que uno necesita del objeto que al otro pertenece, y viceversa [...] y lo que se da para utilidad común no ha de ser para daño de uno y ventaja del otro; y por tanto el contrato debe establecerse con base en la igualdad del objeto. Y la medida de las cosas útiles al hombre se indica por el precio, para lo cual se inventó la moneda [...]. Por tanto, si el precio excede el valor del objeto, se sobrepasa la igualdad propia de la justicia. Por tanto, vender más caro o comprar más barato que el precio real del objeto, de suyo es injusto e ilícito” Aquino (2008) p. 303. 
acuerdos que, por ser manifiestamente inequitativos, pongan en evidencia la insatisfacción del interés de un contratante, normalmente el más débil”7.

De esta forma, el equilibrio entre prestaciones se transforma en un criterio interpretativo, que permite orientar la labor judicial y, poco a poco, comienza a ser considerado como un principio básico del ordenamiento ${ }^{48}$. En consecuencia, al adquirir tan importante categoría, permite a la doctrina volver a apreciar a las herramientas jurídicas que resguardan este principio, entre las cuales se cuenta, por cierto, la rescisión por lesión ${ }^{49}$.

\section{CÓMO LOGRAR UN EQUILIBRIO ENTRE AUTONOMÍA DE LA VOLUNTAD Y JUSTICIA CONTRACTUAL}

La autonomía privada y la justicia contractual son principios clave del Derecho de contratos y ambos principios deben manifestarse en forma equilibrada, de tal manera que permitan conjugar la necesaria libertad de las partes para autodeterminarse con las exigencias de justicia que emanan del contrato.

\section{ReSTRICCIONES O LiMitaCiONES A LA AUTONOMÍA DE LA VOLUNTAD}

Tal como lo ha expresado FerRI, "el problema de la autonomía es, ante todo, un problema de límites, y de límites que son siempre el reflejo de normas jurídicas, a falta de las cuales el problema no podría siquiera plantearse, a menos que se quiera identificar la autonomía con la libertad natural o moral del hombre" ${ }^{50}$.

La autonomía privada no es un poder originario y soberano, sino que es un poder conferido a las personas por una norma superior, la cual se encarga de regular su actuación, estableciendo cargas y limitaciones. Esa norma superior es la ley, la que puede ampliar el campo de actuación de la autonomía privada o restringirlo; incluso actuando con posterio-

\footnotetext{
47 Martín (1995) p. 33. In fine, continuando este camino recorrido hacia atrás, encontramos la idea aristotélica de la justicia correctiva, que impone la necesidad de obtener un justo medio entre una cierta ganancia y pérdida en las transacciones voluntarias Véase ARISTÓTELES (2014) p. 187.

48 Confrontar Martín (1995) p. 33.

49 En tal sentido, en cuanto al fundamento de la rescisión, AlberRUCHE se decanta por la teoría que postula como fundamento "la consecución de una equidad en las prestaciones, que, en el caso de la rescisión por lesión, trata de solventar el desequilibrio económico que ha tenido lugar en el contrato por la situación de inferioridad en la que se encontraba una de las partes, y reparar así un determinado perjuicio" [AlberRUCHE (2010) p. 175].

50 Ferri (2001) p. 5. En contra, opina Martín Pérez, para quien el método de atenuar las consecuencias del dogma de la libertad acudiendo a las limitaciones, merece ser criticado. En primer lugar, "porque cualquier iniciativa legislativa que trate de corregir la disparidad y proteger al más débil sin alterar la previa atribución de poderes, acaba traduciéndose en una contradicción del principio de libertad, pues estaría restringiendo el ámbito de poder previamente atribuido, al menos para una de las partes". Y, en segundo lugar, "como consecuencia de lo anterior, cuando aumentan las medidas restrictivas, se acentúa la necesidad de reafirmar que tales desviaciones tienen un carácter excepcional, que son meras intervenciones del legislador de carácter correctivo que tienden a resucitar las condiciones necesarias para la plena operatividad del principio de libertad, sin poner a prueba el valor mismo del principio”. De esta forma, para el autor, el carácter excepcional que presentan estas restricciones, permitiría la continuidad del principio MARTín (1995) pp. 36 y 37.
} 
ridad, al modificar el contenido de una norma negocial ya establecida por las partes ${ }^{51}$. De modo que la libertad negocial no es una libertad o potestad natural del individuo, sino una libertad derivada del Estado; es una libertad jurídica ${ }^{52}$.

En Chile, la ley impone tres tipos de limitaciones o restricciones a la autonomía privada. En primer lugar, se encuentra la prohibición a los particulares de modificar los elementos de la esencia de los contratos, pues, si lo hacen, estos no producirán efecto alguno, o degenerarán en otro diferente (art. 1444 del Código Civil). En segundo lugar, encontramos también las limitaciones impuestas por las leyes, fundadas en el orden público, la moral, o la defensa de las buenas costumbres ${ }^{53}{ }^{54}$. Una concreción de esto último puede verificarse por la aplicación del art. 1682 del Código Civil, que sanciona con nulidad absoluta al contrato que adolezca de objeto o causa ilícita. Finalmente, tenemos las limitaciones impuestas por la creación de tipos contractuales que restringen el ámbito de actuación de la libertad contractual; ya sea reduciéndola, en propiedad, como ocurre con los denominados contratos forzosos ortodoxos ${ }^{55}$, o incluso eliminándola por completo, como ocurre con los contratos forzosos heterodoxos ${ }^{56}$.

Si bien, miradas desde la óptica aportada por la economía liberal del «laissez faire», las limitaciones a la autonomía privada fueron consideradas como atentados a la libertad de la persona, se transformaron en un elemento decisivo al momento de solicitar la intervención del Derecho para que el contrato permitiera una justa composición de intereses ${ }^{57}$.

Pese a todo lo anterior, el considerar que los factores que articulan la intervención de los contratantes para fijar el contenido del contrato son solo límites a la autonomía privada, no resulta todavía suficiente para lograr un adecuado equilibrio de intereses entre dos sujetos. Porque habría que reconocer que estos límites emanarían también de su propia naturaleza, en cuanto conforman una garantía para impedir que su ejercicio acabe desvirtuándola. Cabe, por tanto, plantearse ahora la legítima duda acerca del contenido de la libertad contractual y sobre el lugar que esta ocupa en la teoría del contrato.

51 Confrontar Ferri (2001) p. 43. En tal sentido, se ha expresado que la libertad de los individuos para manifestar su voluntad jurídica tiene todas las limitaciones que -expresa o implícitamente- ha establecido el Derecho, en resguardo de la organización misma del Estado, de sus instituciones fundamentales, del orden público y de las buenas costumbres Confrontar LEÓN (1963) p. 80.

52 Confrontar FERri (2001) p. 44.

53 Confrontar Troncoso y Álvarez (2014) p. 11; López (2003) p. 109.

54 Entre las normas del Código Civil que hacen referencia al orden público, la moral, o las buenas costumbres como limitaciones a la autonomía de la voluntad, encontramos el artículo 880, el art. 1461, el art. 1467, el art. 1475 y el art. 1717 .

55 El contrato forzoso ortodoxo es un contrato impuesto en el que se recibe un mandato heterónomo de concluir un contrato, conservando la facultad de escoger a la contraparte y negociar con ella todas o algunas de las condiciones de la contratación. Es lo que ocurre, por ejemplo, con la obligación que pesa sobre el usufructuario de rendir caución de conservación y restitución, según dispone el art. 775 inc. $1^{\text {o }}$ del C.C. [Confrontar LópEZ (2003) p. 110.

56 El contrato forzoso heterodoxo es aquel establecido íntegramente por la ley, sin haber consentimiento, ni elección del cocontratante, ni discusión de sus cláusulas. Un ejemplo de este tipo de contratos es la hipoteca legal que nace en virtud de lo dispuesto por el art. 662 del C.P.C. Confrontar López (2003) pp. 110 y 112.

57 Confrontar Martín (1995) p. 36. 


\section{NECESIDAD DE UNA NUEVA CONCEPCIÓN DE LA AUTONOMÍA PRIVADA}

Hoy se reconoce que la llamada "crisis de la autonomía privada", que durante un tiempo se achacó a causas externas a ella -como eran el intervencionismo y las frecuentes limitaciones-, proviene de su propia naturaleza ${ }^{58}$. La causa real de dicha crisis son los extremos a los que se condujo el dogma de la autonomía de la voluntad, los que produjeron el colapso del principio, traicionado por el desequilibrio presente en los contratos y la desigualdad económica en que las partes se encontraban.

La autonomía privada fue considerada por la doctrina tradicional como algo preexistente a la valoración del ordenamiento, el que solo podía reconocerla y tutelar los actos emanados de aquella. Hoy, en cambio, se sostiene que aquella es creada por el ordenamiento, el cual establece el ámbito del poder atribuido y la forma en que debe ejercitarse ${ }^{59}$.

En consecuencia, la autonomía privada es el resultado de un juicio de valor, de modo que la ley protege y otorga efectos a la regulación predispuesta por las partes solo en cuanto persiga intereses objetivamente dignos de tutela ${ }^{60}$. En otras palabras, la autonomía privada se convierte en un instrumento dirigido a realizar un interés público ${ }^{61}$.

Existe, además, una revaloración de la exigencia de justicia contractual. Así, hoy puede decirse que esta exigencia de justicia forma parte de la propia esencia de la autonomía privada, insertándose en el principio -junto a la libertad contractual- para justificarla y legitimarla ${ }^{62}$.

En el esquema antiguo, que entendía las exigencias de justicia como limitación a la autonomía privada y como excepciones, cuando el juez aplicaba una norma de justicia, estaba suspendiendo la aplicación de otras normas de habitual aplicación, derivadas del principio general ${ }^{63}$. Incluso, una positivización de una exigencia de justicia sería vista como contraria a la libertad contractual previamente establecida. Ahora, en cambio, es preciso hacer "una apreciación distinta de las manifestaciones de esa exigencia, por ejemplo, del equilibrio entre prestaciones, porque en cuanto constituye el ideal de una sana circulación de bienes y, sobre todo, de la realización de los intereses de ambos contratantes, representa la justificación y el presupuesto de la autonomía contractual" ${ }^{64}$.

La tutela de la autonomía privada por parte del ordenamiento es cierta, pero bajo la condición de que el contrato no se considere únicamente como un ordenamiento jurídico autónomo y, en cuanto tal, destinado, o bien a una indiferencia respecto al contenido de valor del ordenamiento, ello cuando el juicio de mérito y de conformidad axiológica se concluya en sentido favorable al contenido contractual, "o bien a un enfrentamiento con el ordenamiento, cuando ese juicio de mérito y conformidad axiológica se concluya en sentido contrario al contenido contractual" ${ }^{65}$.

58 Confrontar De Castro (1967) Tomo X, p. 17.

59 Véase, por todos, Ferri (2001) p.9.

60 Confrontar Martín (1995) pp. 38 y 39.

61 Confrontar Grondona (2011) p. 282.

62 Confrontar Martín (1995) pp. 39 y 40.

63 Confrontar Martín (1995) p. 40.

64 Martín (1995) p. 40.

65 Grondona (2011) p. 284. 
En síntesis, al momento de contratar, la autonomía de la voluntad de las partes debe coordinar propuestas que respeten la justicia contractual, puesto que las partes solo pueden y deben actuar de buena $\mathrm{fe}^{66}$.

\section{RELACIÓN EXISTENTE ENTRE RESCISIÓN POR LESIÓN Y AUTONOMÍA PRIVADA}

Una vez concluido que no existe contradicción entre la justicia contractual y la autonomía privada, estamos en disposición de desacreditar el rechazo a la rescisión por lesión -proveniente de los ordenamientos que no la han incorporado en sus normativas- fundado en su presunta incompatibilidad con la libertad contractual.

$\mathrm{Si}$ asumimos que la presencia de un grave desequilibrio entre las prestaciones de un contrato oneroso es, normalmente, el resultado y el síntoma de una alteración en concreto del desarrollo de la autonomía privada, el efecto de la rescisión será precisamente a remediar esa anomalía, al introducir un control de funcionalidad que persigue, en última instancia, respetar el sentido que la operación debía razonablemente tener para ambas partes ${ }^{67}$.

La solución adecuada al problema del desequilibrio contractual no debe considerarse como una derogación del principio pacta sunt servanda ${ }^{68}$, sino, al contrario, como una manifestación de la plena realización de este principio. En tal sentido, la rescisión por lesión no está en una lógica de conflicto, sino que refuerza la libertad de contratación, sirviendo de garantía cuando esta no funcione o lo haga de forma inadecuada ${ }^{69}$.

A mayor abundamiento, al admitir que no puede concebirse un principio preponderante y supremo de libertad contractual, y frente a él pequeñas concesiones a otros principios contradictorios que actúan como límites o excepciones al principio general, puede entenderse que la rescisión por lesión no sea un límite ni una excepción. De este modo, si no se discute la generalidad de la autonomía de la voluntad, tampoco es coherente discutir el carácter general del remedio rescisorio cuando se convierte en un principio indispensable para el adecuado ejercicio de la libertad contractual y para el correcto desenvolvimiento del tráfico, aunque solo pueda actuar en situaciones extremas ${ }^{70}$.

Estamos, sin duda, ante un instrumento de proteccionismo jurídico. Pero esta intervención proteccionista no prescinde de los concretos intereses de las partes, pues cuando la rescisión actúa, lo hace en auxilio de esos intereses y trata siempre de ajustarse a ellos en la medida de lo posible ${ }^{71}$. Muestra de esto último es que permite restablecer el equilibrio en las prestaciones, para que los efectos del contrato puedan permanecer vigentes.

\footnotetext{
66 Confrontar Ordoqui (2011) p. 66.

67 Confrontar Martín (1995) p. 41.

68 Principio que, por lo demás, nunca ha estado falto de limitaciones. Incluso en el Derecho Romano no todo contrato era absolutamente obligatorio, ni en todas las circunstancias. Un contrato de arrendamiento de cosa, por ejemplo, podía ser dejado sin efecto unilateralmente por el arrendatario si el arrendador no cumplía con sus obligaciones; o el arrendador podía expulsar al arrendatario si este último no pagaba el alquiler, etc. Más tarde, los emperadores dieron al vendedor el derecho de rescindir el contrato de compraventa si había vendido un terreno por menos de la mitad de su valor real Confrontar Zimmermann (1990) p. 578.

69 Confrontar Martín (1995) p. 41. En igual sentido, Soto (2008) pp. 111 y 115.

70 Confrontar MarTín (1995) p. 41.

71 Confrontar Soto (2008) p. 114. En sentido similar, LeÓn (1963) p. 296.
} 
Una de las razones que se han dado para justificar el rechazo de la rescisión por lesión es que constituiría un atentado a la seguridad del tráfico jurídico, ya que pondría en peligro la estabilidad de los contratos. Pero también es preciso destacar que la seguridad no es un valor absoluto y que en esa tensión entre la justicia y la seguridad no siempre debe ser sacrificada la primera; de ocurrir esto último, se estaría moldeando un Derecho más interesado en favorecer el intercambio como si fuese un fin en sí mismo, que en procurar su sano funcionamiento ${ }^{72}$.

\section{RESCISIÓN Y FUERZA OBLIGATORIA DEL CONTRATO}

Para lograr la deconstrucción del concepto de rescisión contractual es también necesario superar la aparente contraposición entre aquella y el reconocimiento de la fuerza obligatoria del contrato ${ }^{73}$.

La teoría voluntarista clásica postula que una consecuencia del pacta sunt servanda es la intangibilidad o irrevocabilidad del contrato. Esa fuerza vinculante se impone a las partes, quienes no pueden romper el acuerdo por una voluntad unilateral y arbitraria sino solo por mutuo disenso (art. 1.545 del Código Civil chileno); pero también vincula al juez, quien no puede sino hacer valer las causas legales que le autorizan a poner fin al contrato.

$\mathrm{Al}$ respecto, es importante destacar que cuando se rompe el equilibrio contractual es porque falta uno de los presupuestos de la obligatoriedad del contrato, por ende, ejercitar la rescisión de un contrato lesivo es deshacer un contrato ya carente de fuerza vinculante, aunque pareciera tenerla ${ }^{74}$.

Si miramos el problema desde una perspectiva estrictamente voluntarista, de hipertrofia de la voluntad, la teoría de la lesión es inexplicable. Sin embargo, en un sistema como el actual, la fuerza vinculante no se relaciona solo con el acuerdo de voluntades, sino que se conecta también con el cumplimiento de deberes de buena fe $y$, sobre todo, a exigencias de justicia ${ }^{75}$. De este modo, no cabe aceptar que cuando en un contrato oneroso exista una evidente desproporción entre la prestación y la contraprestación correlativa y que tal desproporción no hay sido querida por las partes, el Derecho "se ponga una venda y se abstenga de intervenir solo porque el contrato es obligatorio para las partes"76.

En consecuencia, la fuerza obligatoria del contrato pierde su carácter absoluto y omnipotente cuando se concilian los principios de justicia y buena fe con la libertad y la responsabilidad individual; porque la justicia material es el fundamento de la rescisión por

\footnotetext{
72 Confrontar Martín (1995) p. 43.

73 Confrontar MarTín (1995) p. 44.

74 Ya lo manifestaba Pothier, en los siguientes términos: "La equidad debe reinar en todas las convenciones, de donde se sigue que en los contratos onerosos, en los cuales uno de los contratantes da o hace alguna cosa para recibir cualquier cosa, como, por ejemplo, el precio de la cosa que da o hace, la lesión que sufre uno de los contratantes, aún en el caso de que el otro no haya empleado artificio alguno para engañarle, es bastante en sí misma para considerar vicioso el contrato" POTHIER (1821) p. 103.

75 Confrontar Ordoqui (2011) p. 66.

76 De la Puente (1983) pp. 170 y 171. En un sentido análogo Demontés (1924) p. XI.
} 
lesión y de ello se deriva el hecho de que si desaparece la justicia, desaparece el fundamento y el límite del contrato ${ }^{77}$.

\section{EVOLUCIÓN DE LA NOCIÓN DE CONTRATO}

El concepto de contrato que hoy calificamos de "tradicional", al cual estamos tan habituados y que parece tan natural y tan claro es, sin embargo un concepto reciente ${ }^{78}$. Antes de acuñarse el concepto voluntarista del contrato, transcurrieron largos siglos en los cuales el contrato fue otras cosas distintas ${ }^{79}$, que los historiadores del Derecho, mediante una ardua tarea, han intentado clarificar ${ }^{80}$. Y así como existe una larga tradición anterior a la noción voluntarista de contrato, también existe una concepción posterior, que pone énfasis en la exigencia de justicia en su contenido.

Las nuevas ideas sobre la fuerza vinculante del contrato provocan que el viejo teorema racionalista que asume el contrato como necesariamente justo sufra una evidente inversión en sus factores, determinada por la exigencia de que "solo cuando es justo, es contrato" 81 .

Hoy en día el contrato se plantea como un esquema abierto, que sin duda es el resultado de la confluencia de los intereses de los contratantes, pero que también cumple una función de solidaridad social y permite limitar el ámbito de acción de la autonomía de la voluntad en pos de la tutela de intereses colectivos ${ }^{82}$.

En efecto, el contrato sigue conservando su papel de instrumento clave para lograr la composición de los intereses privados, pero ahora esta labor no se confía única y exclusivamente a los contratantes, sino que está sujeta a un control sobre su justicia por parte de la ley y de los tribunales, que intervienen en su formación para hacer valer otros intereses de corte social, en especial, la buena fe y el equilibrio de las prestaciones ${ }^{83}$. No hay que olvidar que la justicia está por encima de la libertad contractual de las partes y, por tanto, es tarea del Estado - por medio del Derecho- el crear los incentivos necesarios para que las personas se conduzcan con lealtad y honestidad en su transacciones comerciales ${ }^{84}$.

\footnotetext{
77 Confrontar MarTín (1995) p. 49.

78 Confrontar López (2010) p. 13.

79 Para una síntesis de la evolución histórica del concepto de contrato, véase, por ejemplo, el trabajo de LÓPEZ SAnta María, titulado "Aproximación histórica al concepto de contrato" López (2010) pp. 13-74.

80 Confrontar López (2010) p. 13.

81 Martín (1995) p. 49.

82 Confrontar Ordoqui (2011) p. 66.

83 Confrontar Martín (1995) p. 50.

84 Confrontar SoTo (2008) p. 114.
}

En el mismo sentido apuntan las palabras de CAUMONT, quien aboga por una "teoría ética del contrato", en cuanto la noción de contrato tendría siempre un reservorio ético común a cualquiera de sus tipos. El autor señala que: "En cualquiera de sus vicisitudes estructurales y funcionales y en todas las perspectivas conceptuales posibles, el contrato abreva ontológicamente en los manantiales de la lealtad, de la solidaridad, de la cooperación, de la conjunción de sus componentes subjetivos en pos de una finalidad que será no susceptible de alcanzarse si no es, precisamente, mediante el debido respeto a los imperativos de conducta comunitaria que subyacen desde el fondo de los tiempos en el núcleo de todo pacto, configurando su propia definición, constituyendo su propia concepción” CaUmONT (2008) p. 149. 
El contrato es la gran herramienta de la circulación de los bienes económicos, del intercambio producción-consumo; y la propiedad es el medio por antonomasia de gestionar y disfrutar aquellos bienes. Ambos instrumentos, desprovistos de la carga voluntarista y del viejo individualismo, cumplen hoy funciones sociales irremplazables y se someten a las exigencias propias del Estado de Derecho ${ }^{85}$.

Es posible hablar así de una función social del contrato, la que solo llegó a ser ostensible en el siglo recién pasado y que surgió de la comprensión de que el contrato no cumple solo una función económica, sino que también es un medio de colaboración entre los hombres, por cuanto genera, permite o está presente en las interacciones y actividades de las personas ${ }^{86}$.

La rescisión por lesión, en principio, solo pretende realizar la justicia conmutativa: restablecer la equidad en un contrato aislado ${ }^{87}$, sin perjuicio de que con ello se contribuya a evitar disfunciones más amplias del mercado y, sobre todo, evitar una injusticia generalizada y sistemática en la celebración de los contratos ${ }^{88}$.

\section{PARA QUÉ SIRVE LA RESCISIÓN POR LESIÓN}

En contra de la rotunda conclusión extraída por MirabelLi luego de su clásico estudio sobre la rescisión del contrato -que no se sabe de dónde viene, ni lo que es, ni para qué sirve- ${ }^{89}$, consideramos que sí es posible acercarse al conocimiento de su naturaleza y utilidad. En esa senda, efectuaremos a continuación una apretada síntesis acerca de las funciones que ha cumplido la rescisión por lesión en su extensa línea de tiempo y su utilidad frente a otras formas de reparar la lesión contractual.

\section{FunCIONES HISTÓRICAS DE LA RESCISIÓN}

Para entender la aplicación de la rescisión en el día de hoy y justificar su empleo, es preciso examinar su evolución y, en particular, las finalidades y diversos intereses que ha amparado a través de los siglos.

85 Confrontar MarTín (1995) p. 51.

86 Confrontar López (2010) p. 9.

87 En tal sentido, se ha señalado que: "en el intercambio opera el principio de justicia conmutativa, en virtud del cual tiene que respetarse la aequalitas. La igualdad es, pues, inherente a todo contrato que conlleve un intercambio, en definitiva, a lo que se denomina [...] contrato oneroso. El respeto a la igualdad determina la licitud o justicia de cualquier contrato oneroso. De no verificarse la justicia conmutativa, el contrato deviene lesivo para una de las partes" LLÁCER (1992) pp. 33 y 34.

88 Confrontar MarTín (1995) p. 55.

89 Confrontar Mirabelli (1951) p. 3. Otro autor que manifiesta una opinión contraria a la rescisión es, por ejemplo, ManResa y NaVARRo. Al referirse a la lesión, expresa que se trata de "un absurdo económico evidente, defendido por una idea errónea acerca de la equidad. Es un absurdo económico, porque niega las variaciones enormes del precio, empeñándose en fijar sus oscilaciones alrededor de un justo precio, imposible de determinar. En el orden jurídico, [...] conducía a la arbitrariedad, permitiendo o no que se rescindieran los contratos por unos céntimos de diferencia, ponía en tela de juicio la fuerza de los convenios, haciéndola depender de pruebas tan peligrosas como la de testigos y la pericial; y está llena de desigualdades, que, como decía Goyena (sic), patentizan su falta de fundamento, reconocida en las dudas e inconsecuencias de sus defensores" MANRESA (1907) Tomo VIII, p. 740. 
El origen de la rescisión que ha podido conocerse hasta ahora, se asocia, en concreto, a la sanción de la lesión enorme en el contrato de compraventa en el Derecho romano postclásico ${ }^{90}$. Al respecto, han llegado hasta nosotros dos rescriptos de los emperadores Diocleciano y Maximiano, comprendidos en el Codex justinianeo (C.4.44.2 y C.4.44.8). El primero de ellos -clásicamente denominado Lex secunda- aparece fechado en el año 285 d. de C. El otro, dataría del año 293 d. de $\mathrm{C}^{91}$.

Ambos rescriptos, que en el Codex se denominan Leyes De rescindenda venditione constituyen solo aplicaciones aisladas de justicia conmutativa en los contratos. Principalmente, porque constituían respuestas dadas por los Emperadores a casos particulares, sin ninguna intención de aplicar sus soluciones de manera general. Por consiguiente, el principio sancionador de la lesión enorme solo comienza a asentarse con la obra justinianea, gracias a la ampliación del contenido de los textos. En otras palabras, el Corpus Iuris no se limita a recoger una teoría suficientemente perfilada, sino muy por el contrario, sienta las bases para una posterior expansión y perfeccionamiento de la doctrina, de la mano del nuevo concepto de laesio enormis y del pensamiento cristiano.

Esta institución -que en época medieval fue denominada laesio ultra dimidium o laesio enormis ${ }^{92}$ - presenta la paradoja de alcanzar, de un modo simultáneo, dos fines diversos y aparentemente incompatibles entre sí: por un lado, la conservación de los patrimonios en su integridad económica, permitiendo a la vez comerciar con los bienes; y por otro, la conservación del contrato, aunque corregido ${ }^{93}$. La principal característica que presentaba este remedio era, precisamente, que permitía alcanzar ambos fines a la vez, conciliando dos clases de expectativas que parecían irreconciliables.

Sin embargo, la rescisión solo operaba respecto de ciertas personas y ciertas situaciones, constituyendo, por tanto, un verdadero privilegio. Esto ha llevado a algunos a concluir que el devenir de la rescisión no es precisamente una historia de humildes. Porque sus protagonistas, a lo largo del ius commune, fueron nobles adinerados u órdenes monásticas

90 El remedio de la rescisión por lesión tiene su origen en la equidad. Así, ya en la Roma antigua actuaba como un mecanismo correctivo de aquellos contratos que eran válidos según el Ius Civile, pero que causaban efectos injustos e indeseables a una de las partes. En ese contexto, es claro que la función de los antiguos magistrados fue, precisamente, la de dejar sin efecto las expresas estipulaciones de las partes en pos de garantizar la prevalencia de la justicia por sobre lo pactado en condiciones injustas. En tal sentido, es crucial la función que desempeñó la equidad en tiempos de Justiniano -función que permaneció en los siglos venideros- y que la transformó en una especie de justicia a la usanza cristiana y en un mecanismo correctivo de la justicia pagana Biondi (1952) Tomo II, pp. 38-40.

91 Existe gran abundancia de literatura sobre la rescisión por lesión y, pese a ello, pocos autores disienten acerca de que el origen de esta institución se encuentre en las Leyes De rescindenda venditione. Las Leyes De rescindenda venditione son rescriptos imperiales. Es decir, son respuestas dadas por el emperador ante un problema jurídico de un particular. De ambas, la Lex Secunda es la más afamada y citada por la doctrina. Su traducción al castellano es la siguiente: "Si tú o tu padre hubiereis vendido a un precio menor una cosa de mayor precio, es humano que, o restituyendo tú el precio a los compradores, recobres el fundo mediante la autoridad del juez; o bien, si el comprador lo prefiere, recibas tú lo que falta para el precio justo. Parece ser precio menor, si no se ha pagado ni la mitad del precio verdadero".

92 La expresión lesión enorme aparecería por primera vez en Cino de Pistoia [Véase García (1962) p. 27]. En contra, CHAmie, para quien el empleo de la fórmula laesio enormis partiría con Ugolino, en sus Dissensiones Dominorum Véase Chamie (2010) p. 24.

93 Confrontar Martín (1995) p. 70; Alberruche (2010) p. 43. 
con grandes latifundios. Es esta "una historia de ricos dispuestos a arrebatarse las riquezas $y$, al mismo tiempo, interesados en que no se produzcan alteraciones sensibles en sus patrimonios comparados entre sí. La rescisión justinianea gozó de favor en una época feudal en la que el statu quo de la propiedad era la base del Derecho patrimonial. La mayor dosis de protección se otorga a los titulares anteriores, a través de la extensión de las acciones de ineficacia de los actos dispositivos y de las acciones reivindicatorias" ${ }^{\prime 4}$.

Por ese motivo, la rescisión logra mantener la estabilidad de los patrimonios de los contratantes sin impedir la circulación de los bienes, dando como resultado imprevisto que las reglas de ética económica sobre respetar un justo precio en los contratos, de remunerar de manera justa el trabajo, y de rechazar la usura en los préstamos -elaboradas en los primeros siglos medievales y vigentes hasta la Revolución francesa- sirvieran para garantizar la conservación de los bienes en manos de quienes ya los detentaban y mantener el statu quo y la estratificación social ${ }^{95}$.

El advenimiento del racionalismo liberal trajo consigo el abandono de todos los principios de equidad en la contratación, que tenían una profunda raíz ética. Pese a este contexto, la rescisión permanecerá, pero siguiendo el modelo de la Lex secunda, adoptado por el Código Civil francés, en su artículo 1.674; es decir, quedará relegada a las ventas de inmuebles y solo a favor del vendedor. En otras palabras, no se protege a cualquier vendedor lesionado por el contrato, se protege al vendedor propietario, para asegurar la estabilidad de su patrimonio, otra vez en atención a privilegios de clase ${ }^{96}$.

De lo anterior se desprende que, si en su origen la rescisión surgió como una garantía de equidad y de justicia conmutativa, emigró hacia las antípodas, al transformarse en un privilegio odioso, que operaba a favor de quienes menos lo necesitaban y que cooperó en el mantenimiento de las mismas injusticias que pretendía evitar.

\section{Funciones aCtUALES de LA RESCisión EN UNA ECONOMÍA DE MERCADO}

El mayor desafío que presenta, entonces, la rescisión es recuperar el espíritu que la animó en sus orígenes, permitiéndole cumplir la finalidad de protección del contratante más débil y, a la vez, adecuarse a las particularidades de la contratación actual, la que también ha experimentado cambios importantes a lo largo del tiempo.

Para lograr este nuevo posicionamiento de la rescisión, es necesaria una deconstrucción del concepto, que lo articule de modo correcto y lo despoje de mezquindades, purismos y discusiones inútiles, permitiéndole cumplir eficazmente con su finalidad. En esta senda, la función que puede cumplir la rescisión en este nuevo esquema de tráfico económico y jurídico, se deriva de sus dos principales características.

La primera característica es que la rescisión por lesión busca reparar la iniquidad de un contrato que irroga un perjuicio patrimonial injusto para una parte y un enriquecimiento para la otra. Así, "la rescisión mira esencialmente al fenómeno del intercambio y, en particular, a los efectos patrimoniales que se reflejan en la esfera de los contratantes, atribu-

\footnotetext{
94 Martín (1995) pp. 70 y 71.

95 Confrontar MarTín (1995) p. 71.

96 Confrontar MarTín (1995) p. 71.
} 
yendo un alcance a la onerosidad que va más allá de la mera relación de reciprocidad entre ventaja y sacrificio" ${ }^{\prime 9}$.

De esta forma, nace la idea de lesión como ruptura del equilibrio contractual, como una falta de proporcionalidad entre prestaciones, superando, al mismo tiempo, las viejas contradicciones de la rescisión basada en la laesio ultradimidium del Corpus iuris, pues pasa a ser un mecanismo restaurador del equilibrio entre las prestaciones de las partes, aplicable a todo contrato oneroso y en beneficio de ambos contratantes ${ }^{98}$.

La segunda gran característica de la rescisión es la apuesta por lograr la conservación del contrato, que se manifiesta en la posibilidad de corregir el alcance de las prestaciones para restaurar el equilibrio contractual ${ }^{99}$. La denominada reductio ad aequitatem, inherente a la rescisión, concede al contratante demandado judicialmente la posibilidad de dejar subsistente el contrato si corrige la injusticia que ha provocado la lesión sufrida por la contraparte $^{100}$.

Estas dos características se convierten en poderosas razones para reivindicar la utilidad de la rescisión por lesión en la contratación moderna y, especialmente, en la contratación en masa, teñida de una profunda desigualdad entre las posiciones contractuales de las partes. Esta contratación demanda formas de protección y control dirigidas a evitar los abusos a que se ve sometida la parte más débil.

Si bien es cierto que una economía de mercado garantiza un espacio de libre actuación económica y jurídica a los individuos, sin controles directos ${ }^{101}$, no por eso debe abstenerse de asegurar una cierta paridad de poder entre los contratantes ${ }^{102}$. No se trata acá, por tanto, se propiciar conductas puramente altruistas o solidarias, sino de entender que la experiencia nos ha demostrado - una y otra vez- que encomendar al libre juego de la oferta y la demanda la justicia de los contratos ha resultado un completo desastre en términos de la aplicación de justicia en el contrato. Y la justicia debe siempre prevalecer por sobre consideraciones de una falsa seguridad jurídica, disfrazada de serias teorías económicas.

\footnotetext{
97 Martín (1995) p. 73. En igual sentido, Grebieniow (2014) p. 215.

98 Confrontar Martín (1995) p. 73; Grebieniow (2014) p. 215.

99 Confrontar MarTín (1995) pp. 73 y 74.

100 Posibilidad que también incorpora el inciso primero del artículo 1890 de nuestro Código Civil, al establecer que: "El comprador contra quien se pronuncia la rescisión, podrá a su arbitrio consentir en ella, o completar el justo precio con deducción de una décima parte; y el vendedor en el mismo caso, podrá a su arbitrio consentir en la rescisión o restituir el exceso del precio recibido sobre el justo precio aumentado en una décima parte”. Para un análisis pormenorizado de esta figura, véase WALKer (2013) pp. 297-312.

101 En contra, se manifiesta Bullard -exponente del análisis económico del Derecho en el Perú-, para quien: "la lesión es una suerte de control de precios en el que las prestaciones son evaluadas a fin de determinar si han sido fijadas de manera justa o como consecuencia de un aprovechamiento del estado de necesidad [se refiere a uno de los requisitos para que opere la lesión enorme en el Perú]. Pero al hacerlo envía a los agentes económicos el mensaje que los precios o contraprestaciones que pacten pueden ser evaluados por el juez, de la misma manera que lo haría un regulador de precios en un servicio público, solo que incluso con menores herramientas para poder hacerlo" BULLARD (2001) p. 225. Lo que olvida este autor es que una tarificación o control sobre los precios es por su naturaleza algo contingente, a diferencia de la rescisión por lesión, que es por esencia constante. Confrontar Álvarez y Aymerich (1989) p. 23.

102 Confrontar MarTín (1995) p. 75.
} 


\section{CONCLUSIONES}

Si se concibe a la rescisión como manifestación de un afán de justicia conmutativa, que persigue resguardar la buena fe en la contratación y corregir desigualdades odiosas, se encuentra su verdadera utilidad y su genuina fortaleza. Sin embargo, al efectuar un examen panorámico de su historia, es posible advertir que, pese a la nobleza de sus fundamentos, la rescisión ha sido constantemente traicionada o manipulada en su aplicación, para dar paso a la protección de intereses que no requieren el amparo del Derecho. Esto, como es natural, ha abierto un flanco para una crítica injusta y desproporcionada, que ha llevado, incluso, a descartar la adopción de la rescisión en algunos ordenamientos; o en otros casos, a interpretar su normativa de un modo excesivamente restrictivo.

Por otro lado, hoy en día se reconoce que la autonomía privada es el resultado de un juicio de valor, de modo que la ley protege y otorga efectos a la regulación predispuesta por las partes solo en cuanto persiga intereses objetivamente dignos de tutela. También asistimos, en la actualidad, a una revaloración de la exigencia de justicia contractual, la cual se concibe como parte integrante de la propia esencia de la autonomía privada, dado que sirve para justificarla y legitimarla

En el afán de deconstruir el concepto de rescisión subyace una intención de reposicionar a esta forma de ineficacia y reflexionar en torno a su utilidad. Si la estudiamos como una mera anécdota en la historia de la contratación o como un anacronismo, no haremos justicia a la nobleza de su cometido. Por el contrario, si la concebimos como un instrumento para lograr la equidad y para corregir la lesión patrimonial en los contratos, interpretándola de un modo más acorde a su finalidad que a sus detalles, concluiremos que es útil en la corrección de injusticias que, de otro modo, estarían destinadas a perpetuarse.

\section{BIBLIOGRAFÍA CITADA}

Accatino, Daniela (2015): "La 'teoría clásica' del contrato y la discusión sobre su adaptación judicial”, en Revista Chilena de Derecho, vol. 42 No 1. pp. 35-56.

Alberruche Díaz Flores, Ma Mercedes (2010): La rescisión por lesión en el Derecho Civil español (Madrid, La Ley, Primera Edición).

Álvarez Vigaray, Rafael y De aymerich De Rentería, Regina (1989): La rescisión por lesión en el Derecho Civil español común y foral (Granada, Comares).

Aquino, Tomás de (2008): Tratado de la ley, Tratado de la justicia, Opúsculo sobre el gobierno de los Príncipes (trad. Carlos González, México, D.F., Editorial Porrúa, novena edición).

Aristóteles (2014): Ética a Nicómaco (trad. José Luis Calvo Martínez, Madrid, Alianza Editorial, segunda edición).

Barcia Lehmann, Rodrigo (2006): "La autonomía privada como principio sustentador de la teoría del contrato y su aplicación en Chile", en De la MAZA (edit.), Cuadernos de Análisis Jurídico, III. Temas de contratos (Santiago, Ediciones Universidad Diego Portales, Facultad de Derecho) pp. 159-185. 
Barcia Lehmann, Rodrigo (2009): Lecciones de Derecho Civil chileno. De las fuentes de las obligaciones, Tomo II (Santiago, Editorial Jurídica de Chile, reimpresión de la primera edición).

BetTi, Emilio (1975): Interpretación de la ley y de los actos jurídicos (trad. José Luis de los Mozos, Madrid, Editorial Revista de Derecho Privado-Editoriales de Derecho reunidas).

Biondi, Biondo (1952): Il Diritto Romano Cristiano II. La giustizia-le persone (Milano, Dott. A. Giuffrè).

Bullard González, Alfredo (2001): "La parábola del mal samaritano. Apuntes sobre la lesión en el Derecho de contratos", en Themis-Revista de Derecho No 43, segunda época pp. 223-234.

Castejón y Martínez de Arizala, Ángel (1911): Estudio de las nuevas direcciones del Derecho Civil en Italia. Anales de la Junta para ampliación de estudios e investigaciones cientifcas, Tomo VI (Madrid, Establecimiento tipográfico de Fortanet).

Caumont, Arturo (2008): “Teoría ética del contrato. El negocio jurídico contractual como ámbito de eticidad preordenado para la composición autonómica de conflictos de intereses", en Fabricio Mantilla y Carlos Pizarro (Coord.), Estudios de Derecho Privado en homenaje al profesor Christian Larroumet (Santiago, Fundación Fueyo-Universidad Diego Portales; Bogotá, Universidad del Rosario) pp. 137-149.

Chamie, José (2010): "Rescisión por lesión enorme: el problema del origen", en Revista de Derecho Privado No 19 (Bogotá, publicación de la Universidad Externado de Colombia) pp. 5 a 40.

De Castro y Bravo, Federico (1967): El negocio jurídico. Tratado práctico y crítico del Derecho Civil, Tomo X (Madrid, Instituto Nacional de Estudios Jurídicos).

De Castro y Bravo, Federico (2008): Derecho Civil de España. Volumen III. El negocio jurídico y la persona jurídica (Pamplona, Thomson-Civitas, primera edición).

de la Cámara Álvarez, Manuel y Díez-Picazo y Ponce de León, Luis (1988): Dos estudios sobre el enriquecimiento sin causa. Monografías Civitas (Madrid, Editorial Civitas, S.A., primera edición).

De la Puente y Lavalle, Manuel (1983): “La lesión”, en Derecho, No 37: pp. 161-185.

De Martino, Francesco (2005): Individualismo y Derecho Romano Privado (trad. Fernando Hinestrosa, Bogotá, Universidad Externado de Colombia, segunda edición).

Demontés, E. (1924): De la lésion dans les contrats entre majeurs. Etude de droit positif et de législation comparée (Paris, Librairié Générale de Droit et de Jurisprudence).

Díez-Picazo, Luis (2007): Fundamentos del Derecho Civil patrimonial I. Introducción y teoría del contrato (Pamplona, Thompson-Civitas, sexta edición).

Díez-Picazo, Luis y Gullón, Antonio (1995): Sistema de Derecho Civil. vol. I. Introducción. Derecho de la Persona. Autonomía privada. Persona jurídica (Madrid, Tecnos, Octava edición).

Díez-Picazo, Luis y Gullón, Antonio (2012): Sistema de Derecho Civil. vol. II, Tomo I. El contrato en general. La relación obligatoria (Madrid, Tecnos, Décima edición).

Duguit, León (1912): Las transformaciones generales del Derecho Privado desde el Código de Napoléon (trad. Carlos G. Posada, Madrid, Librería española y extranjera de Francisco Beltrán). 
Fernández de Buján, Antonio (2011): Derecho Privado Romano (Madrid, Iustel, cuarta edición).

FERrI, Luigi (2001): La autonomía privada (trad. y notas de Derecho español Luis Sancho Mendizábal, Granada, Comares, S.L.).

Flume, Werner (1998): El negocio jurídico. Parte general del Derecho Civil, Tomo segundo (trad. José María Miquel González y Esther Gómez Calle, Madrid, Fundación Cultural del Notariado, cuarta edición no modificada).

García Vallés, Ricardo (1962): Rescisión por laesio ultradimidium (Barcelona; Bosch, Casa Editorial).

Grebieniow, Aleksander (2014): “La laesio enormis e la stabilitá contrattuale”, en Revue internationale des droits de l'antiquité 61 (Liège, Presses Universitaires de Liège) pp. 195216.

Grondona, Mauro (2011): "Gravedad del incumplimiento, buena fe contractual, cláusula resolutoria expresa: fragmentos críticos y puntos reconstructivos para una defensa antidogmática de la autonomía privada”, en Revista de Derecho Privado No 20: pp. 271-299.

GuZMÁn Brito, Alejandro (2005): “Contribución a la crítica del dogma de la voluntad como fuente de efectos jurídicos. La voluntad específica en los actos jurídicos de derecho patrimonial privado", en Estudios dogmáticos de Derecho Civil: pp. 171-206.

Lasarte, Carlos (1991): Curso de Derecho Civil Patrimonial. Introducción al Derecho (Madrid, Tecnos, tercera edición actualizada).

León Hurtado, Avelino (1963): La voluntad y la capacidad en los actos jurídicos, Colección de estudios jurídicos y sociales, Facultad de Derecho de la Universidad de Chile, vol. XXVII (Santiago, Editorial Jurídica de Chile).

López Santa María, Jorge (2003): "Auge y deterioro de la libertad contractual”, en Cuadernos Jurídicos 18: pp. 107-118.

López Santa María, Jorge (2010): Los contratos, Parte General (Santiago, LegalPublishingThompson Reuters, quinta edición).

Llácer MatacÁs, Ma Rosa (1992): El saneamiento por vicios ocultos en el Código Civil: su naturaleza jurídica (Barcelona, José María Bosch Editor).

Manresa y Navarro, José María (1907): Comentarios al Código Civil español. Tomo VIII (Madrid, Imprenta de la Revista de Legislación, segunda edición, corregida y aumentada).

Martín Pérez, José Antonio (1995): La rescisión del contrato. En torno a la lesión contractual y el fraude a los acreedores (Barcelona, José María Bosch Editor).

Mirabelli, Giuseppe (1951): La rescissione del contratto (Napoli, Casa Edictrice Dott. Eugenio Jovene).

Molina, Luis de (1981): La teoría del justo precio. Edición preparada por Francisco Gómez Camacho (Madrid, Editora Nacional).

Momberg Uribe, Rodrigo (2013): "El control de las cláusulas abusivas como instrumento de intervención judicial en el contrato", en Revista de Derecho; Vol. XXVI- No 1: pp. 377-391.

Montaña Casaní, Amparo (1999): La rescisión por lesión. Origen, evolución histórica y recepción en Derecho Moderno, Tirant Monografías 106 (Valencia, Tirant lo Blanch). 
Ordoqui Castilla, Gustavo (2011): Buena fe en los contratos, Biblioteca Iberoamericana de Derecho (Bogotá, México, D.F., Madrid, Buenos Aires; Editorial Temis, Ubijus, Reus, Zavalía).

Pasquau Liaño, Miguel (2011): "Protección de los consumidores y Código Civil: ¿Integración o distinción?”, en Albiez Dohrmann Klaus (dir.): Derecho Privado Europeo y modernización del Derecho contractual en España (Barcelona, Atelier Libros Jurídicos) pp. 485-508.

Pedrals García de Cortázar, Antonio (2011): "Sobre la 'abstracta y difusa' noción de equidad natural”, en VARAs et al. (coord.), Estudios de Derecho Civil, Jornadas Nacionales de Derecho Civil 2005-2009, Tomo I, (Santiago, Abeledo Perrot- Thomson Reuters) pp. 79-90.

Pedrals García de Cortázar, Antonio (2014): Fundamentos de Teoría General del Derecho (Santiago, Librotecnia).

Pizarro Wilson, Carlos (2004): "Notas críticas sobre el fundamento de la fuerza obligatoria del contrato. Fuentes e interpretación del artículo 1545 del Código Civil chileno", en Revista Chilena de Derecho, Vol. 31 No 2: pp. 225-237.

Pothier, Robert Joseph (1821): Oeuvres complètes. Traité des obligations, nouvelle édition, ornée du portrait de l'auteur, publiée par M. Siffrein, Tome premier (Paris, Chez L'Éditeur).

Pugliati, Salvador (1943): Introducción al estudio del Derecho Civil (trad. de la segunda edición italiana. No se indica el traductor, México, D.F., Porrúa Hermanos y Cía., Distribuidores).

Saleilles, Raymond (1901): De la déclaration de volonté. Contribution a l'étude de l'acte juridique dans le Code Civil allemande (art. 116 à 144) (Paris, Cotillon, F. Pichon, Sucesseur, Editeur Libraire du Conseil d'État et de la Société de Législation Comparée).

Soto Coaguila, Carlos (2008): "El pacta sunt servanda y la revisión del contrato", en Estudios de Derecho Privado en homenaje al profesor Gonzalo Figueroa Yáñez (Santiago, Editorial Jurídica de Chile-Fundación Fueyo, primera edición) pp. 105-132.

Troncoso Larronde, Hernán y Álvarez Cid, Carlos (2014): Contratos. Colección Tratados y Manuales (Santiago, LegalPublishing-Thomson Reuters, sexta edición actualizada).

Walker Silva, Nathalie (2012): "Derecho de opción del contratante vencido en juicio por lesión enorme. Orígenes e interpretación del artículo 1890 del Código Civil”, en Revista Chilena de Derecho, vol. 39, No2: pp. 297-312.

Zimmermann, Reinhard (1990): The Law of obligations. Roman foundations of the civilian tradition (Cape Town-Wetton-Johannesburg, Juta \& Co. Ltd., first edition). 
